This item was submitted to Loughborough's Institutional Repository (https://dspace.lboro.ac.uk/) by the author and is made available under the following Creative Commons Licence conditions.

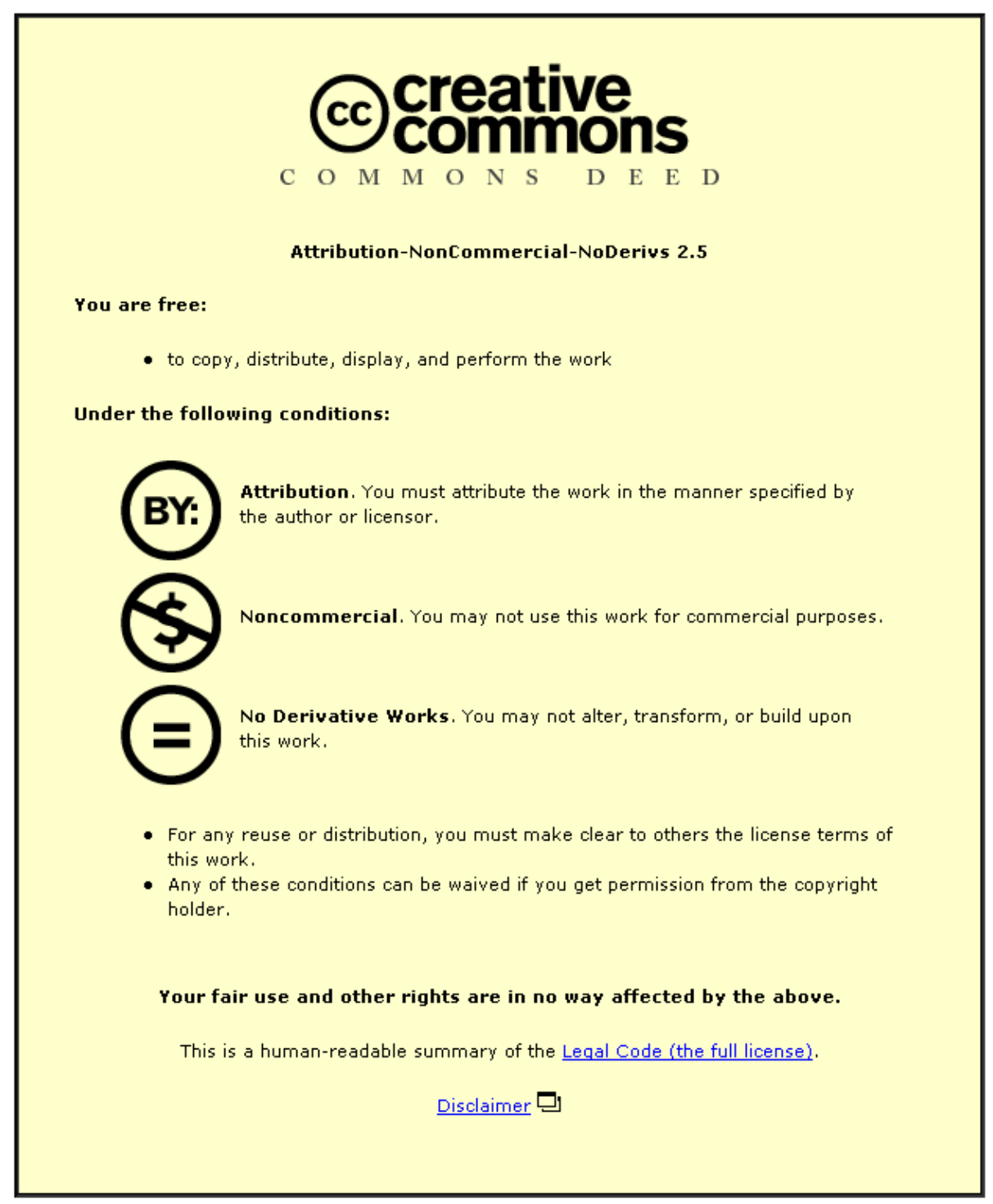

For the full text of this licence, please go to: http://creativecommons.org/licenses/by-nc-nd/2.5/ 


\title{
Printable Windscreen Quad-band GSM Antenna
}

\author{
Chinwe C. Njoku", William Whittow ${ }^{\# 1}$, Chinthana Panagamuwa ${ }^{\# 2}$ \\ "Electronic and Electrical Engineering Department, Loughborough University, Loughborough, LE11 3TU, UK \\ ${ }^{1}$ w.g.whittow@Iboro.ac.uk, ${ }^{2}$ C.J.Panagamuwa@lboro.ac.uk
}

\begin{abstract}
The design and simulation of a suitable GSM antenna for integration with the rear windscreen of a car is presented in this paper. A bent asymmetric dipole antenna was chosen to minimise the surface area and thus cause minimal effect to the aesthetics of the car as well as to the driver's visibility. The antenna has been simulated on a realistic three-layered windscreen. Parasitics were added to the design to improve the bandwidth at 900 and $1800 \mathrm{MHz}$ at both European and American bands. The bent asymmetric dipole was advantageous compared to a straight asymmetric dipole because i) the radiation pattern was more omnidirectional and ii) the parasitics at each band could be designed to work independently of each other.
\end{abstract}

\section{INTRODUCTION}

Modern vehicles include many wireless applications for convenience and entertainment purposes. It is challenging to satisfy the mechanical, aesthetic, electromagnetic and aerodynamic requirements of today's modern car manufacturers and owners, while simultaneously providing as many radio services as necessary such as Global System for Mobile Communications (GSM), Global Positioning System (GPS), remote keyless entry (RKE), Radio and TV, telematics, etc. Whip antennas have previously been used to provide broadcast services but have been replaced by rear screen/glass antennas [1]. Quadrifilar helix (QHA), microstrip, dipole and patch antennas provide navigation in vehicles [2], giving best performance when externally located compared to when cabin-mounted [3]. Short-range wireless services such as remote control engine start, RKE and automatic tolling systems are provided by loop antennas in the side mirrors and rear bumper [4]. Providing all of these services with the optimal antenna at the optimal location will make the car unpractical and less aesthetic. Attempts to mitigate this led to the development of conformal antennas that are hidden on different parts of the car. The glass windows and windscreens are commonly used locations as the antennas are not adversely affected by the exterior metal sections of the car.

Omnidirectional radiation in the azimuth plane is required for car mobile antennas for optimum communication between the mobile unit and the base station and is ideally provided by a mast antenna (monopole) mounted on the roof [5]. The Advanced Mobile Phone System (AMPS) was the first mobile system to be introduced to the automotive industry [6]. Early antenna structures were vertically-mounted on the bumper, boot or roof of the car [7] to minimise shielding. Various GSM antennas designs have been developed for vehicular purposes. The dual-band PIFA designs in $[8,9]$ printable on glass or plastic cannot be used for windscreen purposes because of the antenna's height. References $[10,11]$ present suitable antennas but they have to be mounted externally to the glass and is obstructed by the car body parts. From [10], placing antennas directly on glass reduced the back radiation, minimised EMC problems and increased bandwidth but reduced efficiency and input impedance. Also, variation in glass dimensions increases the difficulty of placing the antenna within the windscreen. Besides AM and FM antennas $[12,13]$, little work has been presented on the rear windscreen for other radio applications such as GSM.

The major GSM frequency bands for the world's mobile telephone markets are: lower band-US 824-894MHz; Europe 890-960MHz; Japan 810-956MHz. The upper band ranges from $1710-1990 \mathrm{MHz}$ except in Japan where it is 1429$1501 \mathrm{MHz}$. This paper proposes a suitable dual-band bent, asymmetric dipole antenna design for integration into the rear windscreen of a car. Parasitics were used to improve the bandwidths at the $900 \mathrm{MHz}$ and $1800 \mathrm{MHz}$ frequency bands to cover the US and European markets.

Empire $\mathrm{XCcel}^{\mathrm{TM}}$ 3-D simulation software was used for the design of the antenna (www.empire.de). Although simulations in this paper do not include a ground plane under the antenna, the ground plane may be an alternative method to improve the bandwidth. This was tested during simulations for the straight asymmetric dipole. However, in this instance, a ground plane was not desirable as this would increase the visibility of the antenna.

\section{EFFECT OF THE WINDSCREEN}

The rear windscreen of a modern car is usually a laminated three-layered structure: two layers of glass separated by a Polyvinyl Butyral (PVB) thinner layer. The cross-section is as shown in Fig. 1. Since the design is based on the asymmetric dipole on glass, the effective dielectric constant of the antenna can be approximated as given by equation (1) [14].

$$
\varepsilon_{e f f}=\frac{\varepsilon_{r e}+1}{2}+\frac{\varepsilon_{r e}-1}{2}\left(\frac{1}{\sqrt{1+12 d / W}}\right)
$$

where $\varepsilon_{r e}$ is the equivalent relative permittivity of the multilayered substrate given in equation (2), $d$ is the thickness of the substrate and $W$ is the width of the microstrip line.

$$
\varepsilon_{\mathrm{re}}=\frac{\sum_{l=1}^{n} h_{i}}{\sum_{i=1}^{n} \frac{h_{i}}{\varepsilon_{\gamma_{l}}}}
$$

where $\varepsilon_{r i}$ is the relative permittivity and $h_{i}$ the height of the $i^{\text {th }}$ layer. The thickness of the windscreen and its equivalent relative permittivity [10], see Fig. 1, were primary factors in 
determining the resonant length of the antenna. There was a considerable decrease in resonant frequency and in $-10 \mathrm{~dB}$ bandwidth when the dipole was in free space compared to when it was placed on the three-layered glass windscreen. The $-10 \mathrm{~dB}$ bandwidth was reduced by $\sim 32 \%$ at both frequencies and the resonant frequency was decreased by $34 \%$ in the $1800 \mathrm{MHz}$ and $30 \%$ in the $900 \mathrm{MHz}$ band. Therefore, there is a trade-off between the dielectric loading advantage of requiring a smaller antenna and the reduced bandwidth which means that covering the required bands is more challenging. The value of $\varepsilon_{\text {eff }}$ from (1) is 3.52. Therefore, the theoretically scaling factor $\sqrt{ }\left(\left(\varepsilon_{\text {eff }}+1\right) / 2\right) \approx 1.5$ which agrees well with the simulated results when the antenna was placed on the windscreen.

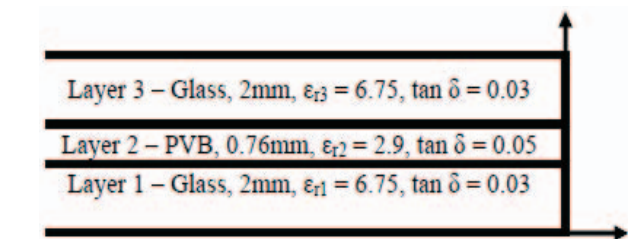

Fig. 1. Cross-section and properties of a rear windscreen

\section{RESULTS}

In this section the results are presented. Initially a straight asymmetric dipole was considered. In the second part of this section, a bent asymmetric antenna is considered. The microstrip asymmetric dipole antenna has a width of $0.5 \mathrm{~mm}$ and thickness of $0.034 \mathrm{~mm}$. Note, all the results presented in this paper are on the three-layer windscreen shown in Fig. 1.

\section{A. Asymmetric Dipole Antenna}

An asymmetric dipole antenna was the initial candidate for a dual band antenna that had a small cross-section and would therefore be relatively invisible. The lengths of the two arms of the antenna were varied until the antenna on the glass substrate resonated at both $900 \mathrm{MHz}$ and $1800 \mathrm{MHz}$. These lengths were 86 and $11 \mathrm{~mm}$, see Fig. 2 (a). Varying the width of the straight asymmetric dipole did not have any significant impact on the resonant frequency or return loss although the bandwidth was slightly affected.

As shown in Fig. 2 (b), there are considerable nulls in the far-field pattern of the straight asymmetric dipole. As an omnidirectional radiation pattern is required for proper operation of the antenna, these nulls were undesirable.

Since microstrip dipoles are inherently narrow bandwidth, it was expected that the antenna would not have the required bandwidth, see Fig. 3. Therefore, the next stage was to broaden the bandwidths at both frequencies. Bandwidth broadening techniques used for microstrip antennas include the use of gap or direct coupled antennas, stacked elements separated by dielectrics, impedance-matching feed networks, and reducing the dielectric constant and increasing the height of the substrate [15]. In this work, parasitics were used as the broadening technique because they would be the simplest method to implement in our car windscreen design. The appropriate parasitics for each band were optimised separately. But when they were combined to form one structure, they interfered destructively with each other, reducing the S11 at 900MHz, see Fig. 3.

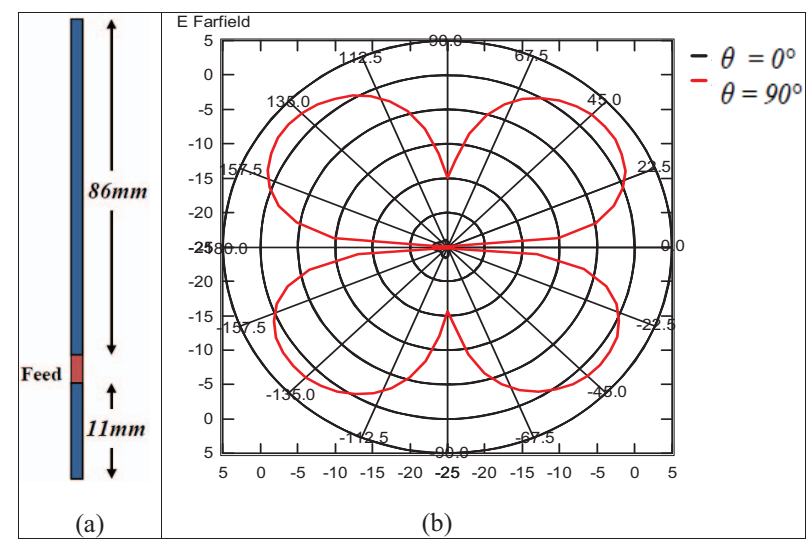

Fig. 2. Straight asymmetric dipole (a) Geometry (b) Radiation pattern at $1800 \mathrm{MHz}$

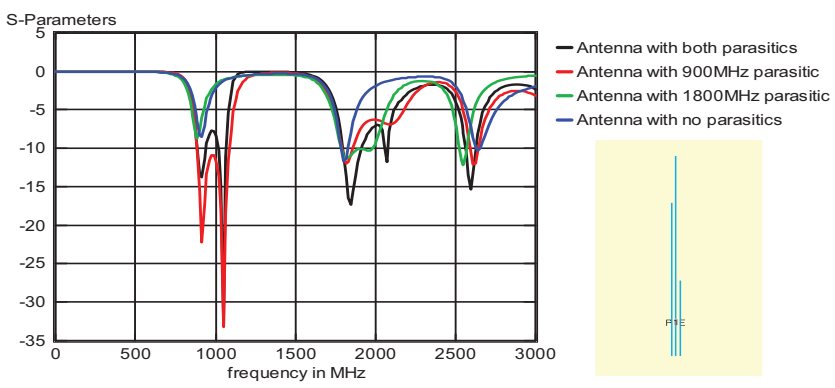

Fig. 3. The return loss of the asymmetric dipole with tuned parasitics. Inset: The geometry (P1E is the feedpoint)

\section{B. Bent Asymmetric Dipole Antenna}

To overcome the problems of the nulls in the radiation patterns and the mutual coupling of the parasitics, the design was improved by using a bent asymmetric antenna. The geometry of the bent antenna and the location of the added parasitic elements are shown in Fig. 4 and the dimensions are shown in Table 1.

The bent antenna was first considered without the addition of parasitics. The length of the bent arm of the stand-alone antenna and the point of its bend were crucial to the return loss values of the structure even when the total length of the antenna was kept constant. Varying the length L1 affected the return loss values and bandwidth at both frequencies. The location of the surface currents on the bent antenna at 900 and $1800 \mathrm{MHz}$ were examined. The maximum currents at $1800 \mathrm{MHz}$ were located at the bottom of the antenna, hence the original $1800 \mathrm{MHz}$ parasitic, L6, was located there to maximise the effect of the parasitic. The maximum current at $900 \mathrm{MHz}$ was located towards the top of the antenna. 


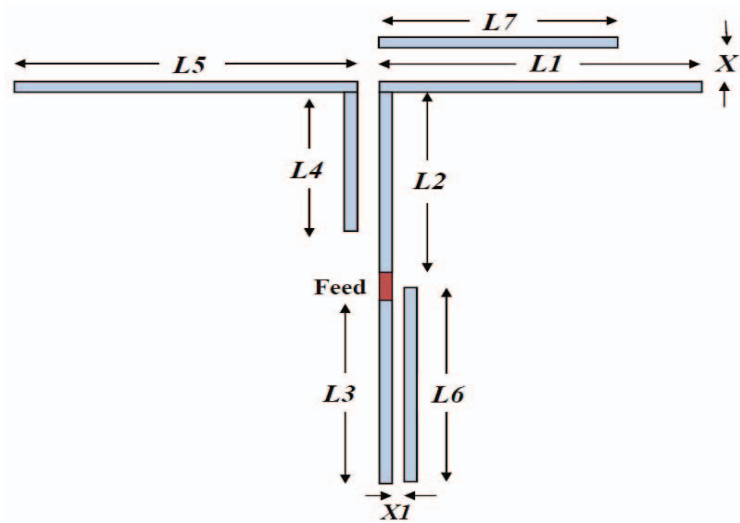

Fig. 4. 2-D view of proposed antenna

TABLE 1. Geometry of antenna designs (mm)

\begin{tabular}{|l|c|c|c|c|c|c|c|c|c|}
\hline & L1 & L2 & L3 & L4 & L5 & L6 & L7 & X & X1 \\
\hline $\begin{array}{l}\text { Bent } \\
\text { antenna }\end{array}$ & 42.4 & 29.5 & 15 & - & - & - & - & - & - \\
\hline Fig. 5 & 58 & 17 & 30 & 23.5 & 58 & $\begin{array}{c}32.8 \\
\text { to } \\
42.8\end{array}$ & - & - & 1 \\
\hline Fig. 6 & 58 & 17 & 30 & 23.5 & 58 & 37.8 & - & - & $\begin{array}{c}0.5 \\
\text { to } \\
5.0\end{array}$ \\
\hline Fig. 7 & 57 & 17 & 30 & 23.5 & 58 & 36.8 & 42 & $\begin{array}{c}0.5 \\
\text { to } \\
8.5\end{array}$ & 0.5 \\
\hline $\begin{array}{l}\text { Final } \\
\text { design }\end{array}$ & 57 & 17 & 30 & 23.5 & 58 & 36.8 & 42 & 2.5 & 0.5 \\
\hline
\end{tabular}

The length and position of the parasitics for each band was obtained separately and then combined into one design. Adding a parasitic, introduced a resonance at an adjacent frequency and by varying its length, the resonance was brought closer to the original resonance until they combined and the bandwidth was increased. After testing several positions, the inverted-L parasitic on the left (L4, L5) affected just the $900 \mathrm{MHz}$ bandwidth without detuning the $1800 \mathrm{MHz}$ band. Varying the distance between the L4-L5 parasitic and the fed antenna affected the $900 \mathrm{MHz}$ S11 (return loss) values only. The length L4 changed the resonant frequency of the parasitic therefore changing the bandwidth. Changing the vertical position of the port while keeping the total length of the fed antenna constant, considerably affected the S11 values at both frequencies. The bottom right parasitic (L6) is responsible for the $1800 \mathrm{MHz}$ band and is completely isolated from the $900 \mathrm{MHz}$ band.

Parametric studies were used to determine the best locations and separation distances for each parasitic. From Fig. 5 and Fig. 6, it can be observed that altering the length or the separation distance of parasitic L6 did not affect the $900 \mathrm{MHz}$ band significantly but only has an effect on the return loss value and bandwidth of the $1800 \mathrm{MHz}$ band. As the distance $\mathrm{X} 1$ increased, the return loss got worse until the parasitic had negligible effect. As the length of L6 increased, it began to adversely affect the $900 \mathrm{MHz}$ bandwidth. The top parasitic (L7) was included to further broaden the bandwidth at $1800 \mathrm{MHz}$, see Fig. 7. There was good isolation between the parasitics.

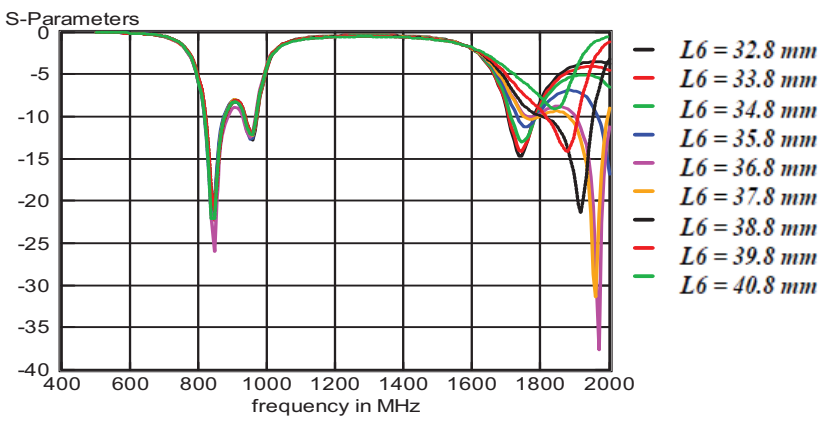

Fig. 5. Varying the length of the parasitic, L6. The antenna includes parasitics L 4 and L5 but not L7 - see Table 1

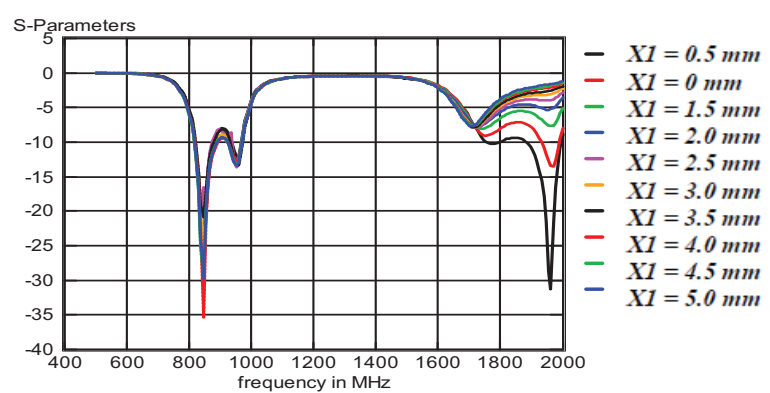

Fig. 6. Varying the separation distance, X1, of parasitic, L6. The antenna includes parasitics L4 and L5 but not L7 - see Table 1

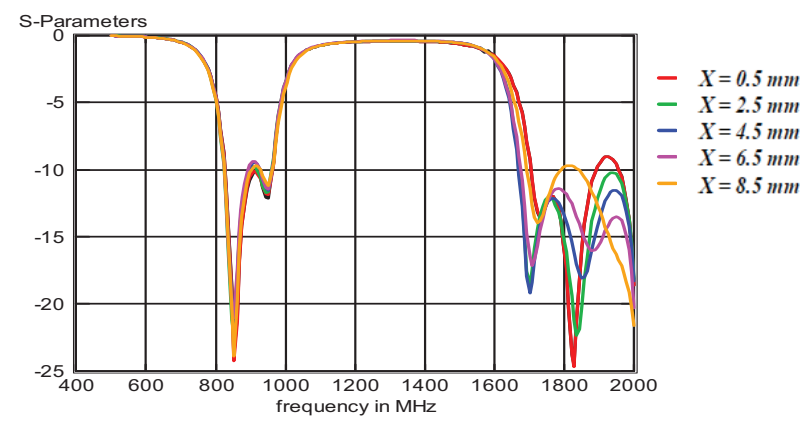

Fig. 7. Varying the separation distance, X, of top parasitic. L7, from fed antenna. The antenna includes all three parasitics - see Table 1

The simulated return loss graphs of the bent antenna alone, with the $900 \mathrm{MHz}$ and $1800 \mathrm{MHz}$ parasitics individually and the final antenna design are shown in Fig. 8. The dimensions of the final antenna design are shown in Table 1 . It can be observed that the parasitics appropriately tuned, created a dual resonance effect its target frequency band which resulted in improved return loss and broader bandwidth at both frequencies. Sufficient bandwidth can be seen over the required GSM bands due to the three parasitics included. For the $900 \mathrm{MHz}$ band, not all the frequencies within the band are 
below the $-10 \mathrm{~dB}$ line but this occurs only over about a $40 \mathrm{MHz}$ frequency range and has a return loss of $-9.06 \mathrm{~dB}$ which is quite acceptable given that some radio equipment manufacturers build their equipment for a $-6 \mathrm{~dB}$ bandwidth performance.

Fig. 9 shows the surface current density for the final design of the windscreen mounted antenna at $900 \mathrm{MHz}$ and $1800 \mathrm{MHz}$ Parasitic L7 can clearly be seen in Fig. 9 (b) at $1800 \mathrm{MHz}$. Parasitic L6 can also be seen at $1800 \mathrm{MHz}$ but it is positioned very close to the antenna and it is therefore quite difficult to distinguish.

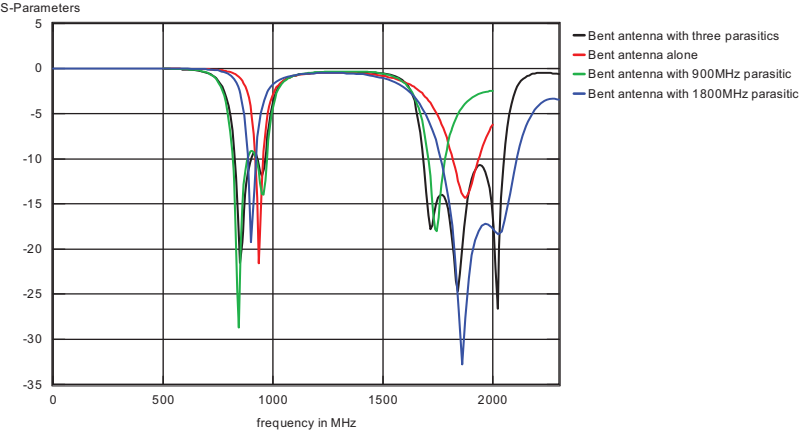

Fig. 8. Return loss for the bent antenna with and without the parasitic

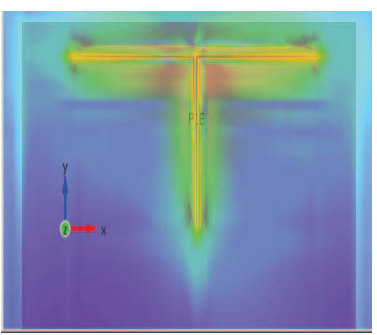

(a)

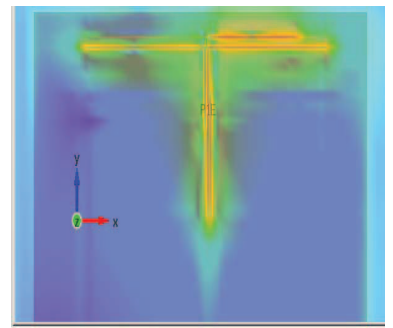

(b)
Fig. 9. Surface current density of final antenna design at (a) $900 \mathrm{MHz}$ (b) $1800 \mathrm{MHz}$

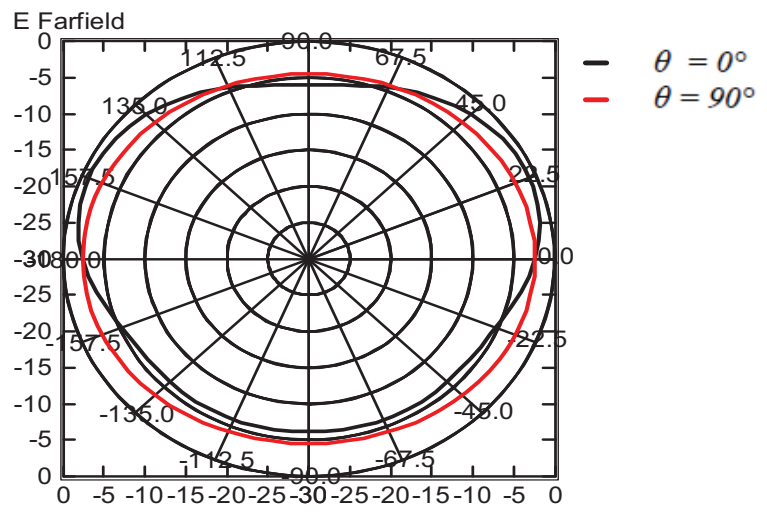

Fig. 10. Far-field radiation pattern of the final antenna design at $1800 \mathrm{MHz}$
Comparing the far-field radiation patterns shown in Fig. 2 and Fig. 10, the nulls present in the straight asymmetric dipole design have been removed by bending the antenna. Also the electric field values in the $0^{\circ}$ and $90^{\circ}$ directions were improved, showing that the bent antenna provides better coverage than the straight asymmetric antenna.

\section{CONCLUSIONS}

A bent, asymmetric, microstrip dipole antenna suitable for integration into the rear windscreen of a car, to cover the GSM frequency bands in Europe and the USA has been designed and simulated on a three layer windscreen. Parasitics were used to broaden the bandwidth. One parasitic was required for the bandwidth at $900 \mathrm{MHz}$ and two were required at $1800 \mathrm{MHz}$ to cover the GSM bandwidth. The lengths and separation distances were optimized. The bent antenna design was advantageous over the straight design as the nulls in the radiation pattern were removed. In addition, the separate parasitics did not couple with each other as they were mutually perpendicular.

\section{REFERENCES}

[1] P. S. Hall, and E. G. Hoare, "Vehicle telematics: the challenges for antennas and propagation", $11^{\text {th }}$ International Conference on Antennas and Propagation, vol. 1, pp. 246-251, April 2007.

[2] K. Fujimoto, and J. R. James, Ch. 8 in Mobile Antenna Systems Handbook, $2^{\text {nd }}$ edition, Norwood MA: Artech House Inc, 2001

[3] R. Kronberger, H. Lindenmeier, L. Reiter, and J. Hopf, "Multiband planar inverted-F car antenna for mobile phone and GPS", IEEE Antennas and Propagation Society International Symposium, vol.4, pp.2714-2717, Jul. 1999

[4] M. Hirano, M. Takeuchi, T. Tomoda, and K. Nakano, "Keyless entry system with radio card transponder", IEEE Transactions on Industrial Electronics, vol. 35, pp. 208-216, May 1988.

[5] L. Economou, and R. J. Langley, "Dual band hybrid vehicular telephone antenna", IEE Proceedings - Microwaves, Antennas and Propagation, vol. 149, no. 1, pp. 41-44, Feb. 2002

[6] T. J. Talty, D. Yingcheng, and L. Lanctot, "Automotive antennas: trends and future requirements", IEEE Antennas and Propagation Society International Symposium, vol. 1, pp. 430-433, Jul. 2001.

[7] R. Kronberger, H. Lindenmeier, L. Reiter, and J. Hopf, "Multiband planar inverted-F car antenna for mobile phone and GPS", IEEE Antennas and Propagation Society International Symposium, vol.4, pp.2714-2717, Jul. 1999

[8] R. J. Langley, "Patch antennas for vehicles", IEE Colloquium on Antennas for Automotives, pp. 9/1-9/6, Mar. 2000.

[9] R. J. Langley, and J. C. Batchelor, "Hidden antennas for vehicles", Electronics and Communications Engineering Journal, vol. 14, pp.253-262, Dec. 2002.

[10] L. Economou, and R. J. Langley, "Circular microstrip patch antennas on glass for vehicle applications", IEE Proceedings - Microwaves, Antennas and Propagation, vol. 145, no. 5, pp. 416-420, Oct. 1998.

[11] R. Leelaratne, and R. J. Langley, "Multiband PIFA vehicle telematics antennas", IEEE Transactions on Vehicular Technology, vol. 54, no. 2, pp. 477-485, Mar. 2005

[12] H. Lindenmeier, L. Reiter, and J. Hopf, "Active AM-FM windshield antenna with equivalent performance to the whip now as standard equipment in car production", IEEE Antennas and Propagation Society International Symposium, vol. 23, pp. 621-624, June 1985

[13] K. Fujimoto, and J. R. James, in Mobile Antenna Systems Handbook, $2^{\text {nd }}$ ed., Norwood MA: Artech House Inc, 2001

[14] D. M. Pozar, Microwave Engineering, 3rd ed., New York, Chichester: John Wiley \& Sons Inc, 1998

[15] R. Garg, P. Bhartia, I. Bahl, and A. Ittipiboon, Microstrip Antenna Design Handbook, Norwood MA: Artech House Inc, 2001 